\title{
SIMBOLISASI TRADISI NGABDUL QODIRAN DI PONDOK PESANTREN AL LUQMANIYYAH YOGYAKARTA:
}

Kajian Living Qur'an

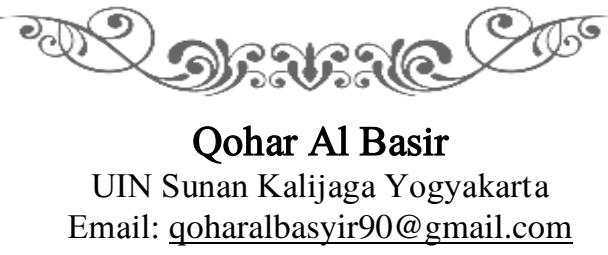

\begin{abstract}
There are many symbols that the writer found in Ngabdul Qodiran tradition which are not found in manaqiban and Shaykh 'Abdul Qodir al-Jailani's haul traditions, which all are the same practices in which their activities use the Wasilah to Shaykh' Abdul Qodir al -Jailani. There are a number of texts that distinguish them one to the others. In manaqiban, the texts read are the history of Shaykh 'Abdul Qodir which were written in the form of a story and syi'ir. In haul, the texts read are Surah Yasin and tahlil texts which are directly sent to the deceased. While in Ngabdul Qodiran tradition, the texts read are selected surahs and dzkir as asmaul husna. In addition, special dishes of Ngabdul Qodiran are inseparable in the series of Ngoddul Qodiran tradition; all of which have their own meanings and contain great wishes. In the phenomenon of Ngabdul Qodiran tradition, it is found that there are symbols which have their respective purposes.
\end{abstract}

Keywords: Shaykh 'Abd al-Qadir al-Jaylanī, Ngabdul Qodiran Tradition, Symbols of Tradition.

\section{Abstrak}

Terdapat banyak sekali simbol-simbol yang penulis dapatkan dalam tradisi Ngabdul Qodiran, yang mana hal tersebut tidak ditemukan dalam tradisi manaqiban dan haul Syaikh 'Abdul Qodir al-Jailani, yang semuanya merupakan amalan yang sama yang dalam kegiatannya menggunakan wasilah kepada Syaikh 'Abdul Qodir al-Jailani. Ada beberapa bacaan yang membedakan satu dengan yang lainnya. Di dalam acara manaqiban, yang dibaca adalah sejarah dari Syaikh 'Abdul Qodir yang berupa cerita dan syi'ir. Di dalam acara haul, yang dibaca adalah Surat Yāsin dan bacaan tahlil yang langsung dikirimkan ke almarhum. 
Sedangkan di acara Ngabdul Qodiran, yang dibaca adalah suratsurat pilihan serta zikir sebagai asmaul husna. Dan ada beberapa hidangan yang khas menu Ngabdul Qodiran yang tidak dapat dipisahkan dalam rangkaian tradisi Ngabdul Qodiran, yang semuanya mempunyai makna sendiri dan mengandung harapan besar. Dalam fenomena tradisi Ngabdul Qodiran, ditemukan simbol-simbol yang mempunyai tujuan masing-masing.

Kata Kunci: Syaikh 'Abd al-Qadir al-Jaylani, Ngabdul Qodiran, Simbol-Simbol Ttadisi.

\section{PENDAHULUAN}

Syaikh 'Abd al-Qadir al-Jaylanī lahir di Jaylan, sebelah selatan laut Kaspia Iran pada tahun 1077 M / 470 H. Selain disebut Syaikh, Wali dan sebutan lain dalam tarekat, ia juga disebut Sayyid. Karena dari pihak ibunya, memeiliki ketersambungan dengan Ḥusayn (cucu Nabi Muhammad Saw.), sedang dari pihak ayah masih keturunan sayyidina Hasan (cucu Nabi Muhammad Saw.). Ia lahir ditengah-tengah keluarga yang sederhana dan sălih. Kakeknya (ayah dari ibunya) bernama 'Abdullāh Sawmi, seorang sufi.

Syaikh 'Abd al-Qadir al-Jaylanī adalah seorang sufi, pelaku tarekat yang kuat, sehingga tidak sedikit dari umat muslim yang ingin meniru dan melakukan apa yang diajarkannya, dalam hal ini ada yang melakukan manakiban, khaul, memperingati hari lahirnya pada setiap tanggal 11 dan ada pula yang melakukan tradisi "Ngabdul Qodiran". Kesemuanya dilakukan oleh masyarakat yang bertujuan untuk mendapat keberkahan dari Syaikh 'Abd al-Qādir. Dari beberapa kegiatan-kegiatan tersebut dapat bermuara pada Syaikh 'Abd al-Qādir, akan tetapi dari masing-masing kegiatan tersebut terdapat berbedaan yang sangat menonjol, contoh saja dalam Ngabdul Qodiran terdapat pembacaan Al-Shams dan Al-Duhā yang dibaca siang hari, terdapat hidangan Nasi kebuli yang sifatnya wajib, sedangkan yang lain tidak wajib. Kemudian perbedaan yang signifikan adalah orang yang memasak hidangan haruslah seoarang perempuan yang sudah menophouse, dan perbedaan lainnya.

Untuk mengetahui perbedaan antara tradisi tersebut adalah, manakiban menurut arti kebahasaan adalah kisah dari kekramatan para wali. ${ }^{1}$ Pada acara tersebut biasa dilakukan dengan membaca manakib Syaikh "Abd al-Qādir. Kemudian kata haul berasal dari bahasa Arab "hawl" artinya adalah "tahun". Sedangkan yang dimaksud dengan perayaan haul adalah acara peringatan hari ulang tahun kematian. Biasanya acara ini diselenggarakan di halaman kuburan mayit yang diperingati atau sekitarnya,

${ }^{1}$ W.J.S Poewardarminta, Kamus Besar Bahsa Indonesia (Jakarta: Balai Pustaka, 1990), hlm. 533. 
tetapi ada pula yang diselenggarakan di rumah, masjid, dan tempat yang lain. Haul pada umumnya diselenggarakan tepat pada hari ulang tahun wafatnya seseorang, yang lazimnya tergolong orang yang berjasa kepada Islam dan kaum muslimin semasa hidupnya. Tradisi haul biasanya berlangsung sampai tiga hari tiga malam yang diisi dengan berbagai macam acara. Namun ada pula yang menyelenggarakannya secara sederhana yang tidak memakan banyak waktu dan biaya dengan hanya diisi pembacaan tahlil dan hidangan makan seadanya. Hidangan yang disuguhkan dalam acara haul adalah hidangan yang diniatkan untuk selamatan atau sedekah dari mayit tersebut. ${ }^{2}$

Berbeda dengan Ngabdul Qodiran yang dilakukan oleh jamaah di Pondok pesantren Al Luqmaniyyah Yogyakrta ini. Tradisi ini dilakukan ketika ada keperluan atau hajat.

\section{PEMBAHASAN}

\section{Tradisi Ngabdul Qodiran di Pondok Pesantren al Luqmaniyyah}

Pondok Pesantren Al Luqmaniyyah adalah salah satu pondok pesantren salaf di Yogyakarta. Dengan basis pembelajaran kajian kitab kuning, Al Luqmaniyyah mempunyai berbagai tradisi kegiatan rutinan yang istiqomah dilaksanakan. Di bawah kepengasuhan Abah Kiai Nai'im Salimi, alumni Pondok Pesantren API Tegalrejo, Abah Kiai tidak hanya fokus mengajar santri-santrinya tetapi juga mengadakan pengajian umum untuk masyarakat sekitar dan tradisi rutinan khusus untuk jama'ah pengajian Abah Kiai.

Ada berbagai macam kegiatan, baik itu acara tahunan seperti acara Harlah al-Tashakur li Ikhtitām dan Haul Abah pengasuh sebelumnya, atau acara selapanan pengajian umum malam Salasa Pon dan tradisi Ngabdul Qodiran, ada juga acara mingguan seperti seperti manaqiban simt al-ḍrrar yang di isi oleh santri-santri Luqmaniyyah. Serta ada lagi rutinan pengajian bapak-bapak jamaah pengajian Abah Kiai setiap malam Rabu. Namun di sini penulis akan lebih memfokuskan pembahasan pada tradisi Ngabdul Qodiran yang pesertanya adalah bapak - bapak jamaah pengajian Abah Kiai.

Istilah Ngabdul Qodiran diambil dari kata 'Abd al-Qadir yang dinisbatkan kepada nama Syaikh Abd al-Qadir al-Jaylanī. Asal-usulnya amalan ini berawal dari Syaikh 'Abd al-Qadir al-Jaylani sendiri yang mengamalkannya ketika mempunyai hajat. Ia melakukannya dengan berdoa bersama-sama dengan jamaahnya. Sebelum acara doa berlangsung Syaikh 'Abd al-Qadir al-Jaylani biasa menjamu jamaahnya dengan jamuan hidangan yang lezat dan nikmat agar hati para jamaah senang dan ikhlas. Dengan

${ }^{2}$ Imron AM, Kupas Tuntas Masalah Peringatan Haul (Surabaya: Al-Fikar, 2005), $13-14$. 
begitu Syaikh 'Abd al-Qadir al-Jaylanī berharap akan dikabulkannya doa yang dipanjatkan dikarenakan ikhlasnya hati orang yang berdoa.

Ngabdul Qodiran yang dilaksanakan di Pondok Pesantren Al Luqmaniyyah ini mengadopsi dari amalan Syaikh 'Abd al-Qadir al-Jaylanī. Pesertanya adalah bapak-bapak jamaah pengajian malam Rabu Abah Kiai Naim. Tujuannya adalah sama, memohon sesuatu kepada Allah dengan melakukan wasilah kepada Syaikh 'Abd al-Qadir al-Jaylanī. Adapun kegiatan Ngabdul Qodiran yang berlangsung di Al Luqmaniyyah ini dilaksanakan dengan membaca surat al-Wāqi'ah, al-Ḍuhāa, al-'Alaq, dan surat al-Zalzalah. Jika kegiatan ini dilakukan pada siang hari, maka bacaanya ditambah dengan surat al-Shams dan al-Ḍuhā. Sebaliknya jika dilakukan pada malam hari maka ditambah dengan surat al-Shams dan alLayl. Setelah itu dilanjutkan dengan membaca sebagian asmā al-husnā yakni (Yà 'A đìm, Yā Mubīn, Yā Hadiyy, dan Yà Khabìi) sebanyak 100 kali. Dilanjutkan dengan membaca shalawat sebanyak-banyaknya sambil menuggu jamaah lain selesai membaca surat-surat tadi.

Seperti amalan Syaikh 'Abd al-Qadir al-Jaylani, tradisi Ngabdul Qodiran di Pondok Pesantren Al Luqmaniyyah ini juga biasa menjamu jamaah dengan hidangan yang berbeda dari biasanya dengan maksud untuk mencari keikhlasn di hati para jamaah. Uniknya dari hidangan dalam acara Ngabdul Qodiran ini, ada menu spesial yang selalu sama setiap kegiatan ini dilakukan. Di antaranya adalah ayam kampung jago dan tujuh macam sayur yang terdiri dari ayam santan, ayam goreng, sayur bakmi, sayur capcay, tempe bacem, telur ceplok, sayur kothok.

Selain tujuh jenis sayur tersebut, berbagai jajanan pasar dan buahbuahan juga sudah tersaji di tengah majelis. Hal ini diharapkan ketika jamaah melihat makanan begitu banyak maka sebagai manusia akan tumbuh rasa keikhlasan dalam diri jamaah. Sedang dalam bahasa jawa, tujuh itu pitu. Pitu menunjukkan arti pitulungan atau pertolongan. Semua menu tersebut dimasak dan disiapkan oleh para abdi ndalem santri putra dan putri Al Luqmaniyyah dan didampingi oleh ibu-ibu lanjut usia penderek Abah Kiai sebagai juruk masak ndalem. Namanya Mbah Hindun, ia masih dhurriyah kelaurga Abah Kiai.

Menu unik lainnya adalah nasi kebuli yang diambil dari kata qobul yang dalam bahasa Arab artinya diterima apa yang didoakan. Nasi kebuli adalah nasi yang cara masaknya dibumbui dengan santan dan garam sehingga rasanya gurih. Serta tak lupa ditambah dengan kecap sehingga warna nasinya menjadi kehitam-hitaman. Cara menanak nasi kebuli juga berbeda dari nasi pada umumnya. Ada syarat-syarat yang harus dipenuhi yakni sebelum memasak harus wudhu dulu dan dimasak oleh orang yang menopouse (sudah tidak haid). Selama memasak dilarang berbicara dan harus membisukan diri. Hal ini untuk menghindari dari perkataan yang yang 
tidak baik. Serta selama memasak harus memakai pakaian serba putih yag bertujuan agar makanan bersih dan higienis meski syarat ini tidak terlalu diutamakan. Khusus untuk menu ini dimasak oleh Mbah Hindun yang usianya memang sudah lanjut usia dan sudah tidak haid.

\section{Pelaksanan Ngabdul Qodiran}

Ngabdul Qodiran di Pondok Pesantren Al Luqmaniyyah ini biasa dilaksanakan setiap malam Senin Pon pada jam 23.00 WIB setelah acara madrasah diniyah Pondok telah usai atau waktu-waktu tertentu sesuai permintaan shohibul hajat seperti Haji, Umroh dan Tujuh bulanan. Pesertanya adalah tamu undangan jamaah pengajian Abah Na'im yang berasal dari luar pondok. Jamaah duduk melingkar di tepi ruangan tamu Ndalem. Semua hidangan diletakkan di tengah-tengah para jamaah dengan posisi terbuka tanpa tutup agar ada doa yang dipanjatkan bisa meresap ke dalam hidangan tersebut. Jadi sering dikatakan dengan makanan yang mengandung doa.

Acara baru akan di mulai ketika Abah Na'im sudah hadir dalam majelis. Diawali dengan pembagian pembacaan surat yang diwakilkan oleh beberapa orang yang sudah ditunjuk. Kemudian Abah Na'im berTawașșul kepada Nabi, Syaikh 'Abd al-Qadir al-Jaylanī, para alim ulama dan kepada semua umat muslim dan muslimat. Kemudian jamaah membaca bagian surat yang sudah di bagi sementara lainnya membaca sholawat sebanyakbanyaknya sampai yang mendapat bagian membaca surat sudah selesai. Acara di akhiri dengan doa penutup yang dipimpin oleh Abah $\mathrm{Na}^{\prime} \mathrm{im}$. Setelah itu dilanjutkan dengan acara menyantap hidangan yang sudah mengandung doa tadi. Semua hidangan dikeluarkan dari ndalem lalu diracik menjadi sajian piringan siap saji lengkap dari tujuh macam sayur oleh para santri putri yang sudah mendapat jadwal rewang acara ndalem. Sebelumnya dipisahkan terlebih dahulu satu porsi Pak Kiai untuk memuliakannya. Baru setelah itu hidangan dibagikan kepada para jamaah.

Pada mulanya, amalan ini hanya dihadiri oleh tujuh orang saja dengan semua memakai pakaian serba putih. Kemudian jumlah jamaah semakin bertambah banyak. Untuk saat ini jumlah jamaah tetap Ngabdul Qodiran Pondok Pesantren Al Luqmaniyyah ada sebanyak 25 orang.

\section{Memaknai Tradisi Ngabdul Qodiran}

Bagi Clifford Greettz selain merupakan fenomena budaya suatu masyarakat, tugas antropolog adalah menemukan makna dalam yang ada di dalam fenomena tersebut, berdasarkan apa yang diketahui, dirasakan, dan dialami oleh pelaku budaya. Inilah yang disebut Greettz sebagai from the 
native's ponit of view, yang merupaka hakikat dari pemahaman antropologis. $^{3}$

Proses menemukan makna di balik simbol-simbol kehidupan yang diekspresikan oleh masyarakat dan memahaminya dari sudut pandang mereka merupakan konsep dari antropologi interpretatif. Melalui simbol, ide dan adat istiadat Greetts menemukan pengaruh agama berada di setiap sudut kehidupan masyarakat. ${ }^{4}$ Greettz mengemukakan teorinya bahwa Agama sebagai satu sistem kebudayaan, mendefinisikan bahwa agama adalah:

\begin{abstract}
"A religion is (1) a system of symbols which act to (2) establish powerfull perpasive and long lastinf moods and motivation in men by (3)formulating conception of general orderof existence and (4) clothing this conception with such an of aura factuality that (5) the moods and motivation seem uniquely realistic" 5
\end{abstract}

"Agama merupakan (1) satu sistem simbol yang bertujuan untuk (2) menciptakan perasaan dan motivasi yang kuat, mudah menyebar dan tidak mudah hilang dalam diri seseorang (3) dengan cara membentuk konsepsi tentang sebuah tatanan umum eksistensi dan (4) melekatkanakan konsepsi ini kepada pancaran-pancaran faktual, (5) dan pada akhirnya perasaan dan motivasi ini akan terlihat sebagai suatu realitas yang unik.

\title{
1) Memuliakan Ulama
}

Hampir semua amalan-amalan yang menjadi tradisi yang dilakukan oleh santri Pondok Pesantren atau Jamaah pengajiannya adalah tradisi yang dibawa dan diajarkan oleh Abah Kiai. Dari generasi ke generasi, para Kiai menganjurkan dan mengajak santri dan jamaah pengajian untuk melakukan tradisi, termasuk Ngabdul Qodiran. Dengan peran Abah Kiai tersebut, santri dan para jamaah selalu berusaha untuk melestarikan tradisi yang telah diajarkan oleh Abah Kiai.

Bagi santri pondok pesantren dan jamaah, Kiai mempunyai otoritas yang tinggi dalam hal keagamaan. Karena otoritas itulah, santri dan jamaah merasa perlu memuliakan para Kiai dengan mengamalkan tradisi yang telah diajarkan dan meminta doa atau "ngalap barokah" kepada para Kiai. Sebagaimana yang telah disampaikan Kang Abdullah

${ }^{3}$ Nur Syam, Madzhab-Madzhab Antropologis (Yogyakarta: Lkis, 2011), 93.

${ }^{4}$ Daniel L. Pals, Seven Theories of Religion n.d, 341.

${ }^{5}$ Clifford Greettz, The Interpretation od Cultures (USA: Basic Book , 1973), 90. 
selaku abdi ndalem, bahwa dengan memuliakan ulama, orang akan mendapatkan kebaikan dan keberkahan. Kalaupun tidak sampai pada dirinya yang memetik buahnya, mungkin anak-anaknya, atau cucucucunya kelak yang bakal mendapatka keberkahan hidup buah dari sang kakek yang memuliakan ulama. ${ }^{6} \mathrm{Di}$ sinilah terlihat bagaimana peran sentral seorang Kiai dalam tatanan kehidupan sosial masyarakat secara umum, tidak hanya sebatas dalam lingkungan pesantren. Bahkan peran tersebut tidak hanya menyangkut urusan keagamaan, tetapi juga dalam hal sosial, ekonomi, budaya, maupun politik. Peran sentral inilah yang oleh Greettz kemudian memberikan istilah Kiai sebagai "Cultural Broker" bagi masyarakat Indonesia. ${ }^{7}$ Selain itu pandangan pandangan ini secara substansi, juga dipengaruhi oleh konsep agama tentang keutamaan memuliakan ulama. Salah satu konsep tersebut terdapat di dalam hadis yang diriwayatkan oleh al-Khātib al-Baghdadi dari Jabir r.a yang artinya: "Nabi Saw bersabda: "Barang siapa memuliakan orang 'alim, berarti ia telah memuliakan aku. Barang siapa yang memuliakan aku berarti memuliakan Allah. Barang siapa memuliakan Allah, maka tempat kembalinya adalah surga."

Hadis di atas menjelaskan bahwa barang siapa yang memuliakan ulama maka akan masuk surga, sebagai tempat kembali. Sementara santri dan jamaah memahaminya sebagai cara untuk mendapatkan keselamatan, kebaikan, dan keberkahan. Di sini telihat suatu ultimate meaning, yaitu memperoleh keselamatan, kebaikan dan keberkahan.

\section{2) Birr al-Wālidayn}

Selain memuliakan para Kiai, santri, dan jamaah pengajian, Abah juga berusaha untuk berbuat baik kepada orang tuanya. Salah satu caranya, dengan menjaga dan melestarikan tradisi yang telah diajarkan oleh para orang tua pendahulu mereka. Menurut Kang Abdullah, dengan berbuat baik kepada orang tua, ia yakin bahwa nanti anak-anak mereka juga akan berbuat baik kepadanya. Dalam hal ini meneruskan tradisi yang ada, diyakini menjadi bagian dari kepatuhan dan ketaatan kepada orang tua. Melalui tradisi Ngabdul Qodiran Kang Abdullah selaku abdi ndalem yang sering menyiapakan acara Ngabdul Qodiran, menyakini bahwa selain mendapatkan untuk diri sindiri pahala yang diperoleh juga akan mengalir kepada orang tua mereka. Dengan demikian, terdapat

${ }^{6}$ Diolah dari hasil wawancara dengan Kang Abdullah selaku abdi ndalem pada tanggal 22 Mei 2019.

${ }^{7}$ Nur Kafid, "From Personal to Social Tranformation: A Phenomenological Study on The Life of 'Kyai Kampung', “Jurnal Komunitas:Research \& Learning In Sociology And Anthropology 6, No 2. (2014): 336-344.

Vol 7, No. 02, Desember 2019 
suatu ultimate meaning dari konsep tentang birr al-wālaidayn, yaitu mendapatkan kebaikan dan pahala. ${ }^{8}$

\section{3) Aura Faktualitas}

Greettz mengatakan bahwa agama atau perspektif religius memperdalam pemusatan perhatinnya kepada fakta dan berusaha menciptakan aura faktualitas (mengandung kenyataan atau kebenaran). Pengertian tentang sesuatu yang "sungguh nyata" ini adalah pusat dari kegiatan-kegiatan yang disimbolkan oleh agama. ${ }^{9}$

Konsep agama tentang memuliakan ulama yang sudah ada di Pondok Pesantren memunculkan aura faktualitas sehingga akan tampak sebagai konsep yang dipercaya mengandung kebenaran. Konsep tentang otoritas atau kemuliaan ulama, memiliki landasan dari hadis Nabi yang menyatakan bahwa orang yang memuliakan ulama akan mendapatkan surga sebagai tempat kembali. Landasan inilah yang membuat konsep tersebut memunculkan aura faktualitas, sehingga dipercaya sebagai konsep yang benar dan nyata.

\section{Simbolisasi Tradisi Ngabdul Qodiran}

Pertama, yang dimaksud Greettz dengan "sebuah sistem simbol" adalah segala sesuatu yang memberi seseorang ide-ide. Dalam konteks ini tradisi Ngabdul Qodiran yang secara rutinitas dilakukan oleh jamaah Pondok Pesantren Al Luqmaniyyah Yogyakarta adalah sebuah ide yang datang atas fenomena amalan rutin dari Syaikh 'Abd al-Qadir al-Jaylanī, bagaimana ia menjamu tamunya untuk mencari keikhlasan mereka agar doa bisa terkabul.

Kedua, saat dikatakan bahwa simbol-simbol tersebut "menciptakan perasaan dan motivasi" yang kuat dan mudah menyebar dan tidak mudah hilang dalam diri seseorang, kita dapat meringkaskannya dengan mengatakan bahwa agama menyebabkan seseorang merasakan atau melakukan sesuatu. Motivasi tentu memiliki tujuan-tujuan tertentu dan orang yang termotivasi tersebut akan dibimbing oleh seperangkat nilai tentang apa yang penting, yang baik dan buruk, yang benar dan salah bagi dirinya. Dalam konteks ini, jamaah Ngabdul Qodiran mengenal konsep keutamaan membaca Alquran. Konsep-konsep ini memunculkan aura faktualitas dan dirumuskan ke dalam simbol-simbol . Simbol-simbol yang dirumuskan itu, disampaikan secara persuasif oleh para Kiai. Mereka mengajarkan, mengajak, dan memberikan ijazah kepada generasi penerus. Agar menjalankan tradisi Ngabdul Qodiran tersebut. Penyampaian simbol-

${ }^{8}$ Hasil wawancara dengan Kang Abdullah selaku abdi ndalem, 22 Mei 2019

9 Clifforz Greettz Kebudayaan dan Agama (Terj), ed. Fransisco Budi Hariman (Yogyakarta: Kanisius, 1992), 32. 
simbol itu, kemudian memotivasi seseorang untuk ikut melaksanakan tradisi tersebut.

Suatu sistem simbol adalah segala sesuatu yang memberikan ide-ide kepada seseorang. Dalam konteks ini ide-ide itu bersumber dari konsepkonsep agama. Konsep-konsep agama yang mengandung ultimate meaning, kemudian memunculkan aura fuktualitas pada tahap selanjutkan dirumuskan dalam bentuk simbol. Simbol ini kemudian disampaikan oleh otoritas dengan gaya persuasif, yang menyarankan suatu gaya hidup atau gaya tindakan tertentu. Dalam konteks ini tindakan tersebut berupa pelaksanaan tradisi Ngabdul Qodiran. Adapun simbol-simbol yang terdapat dalam Ngabdul Qodiran adalah sebagai berikut:

\section{1) Simbol Surat Alquran}

Alquran mempunyai peran yang sangat penting bagi umat Islam. Selain sebagai sumber ajaran, Alquran juga diyakini sebagai mukjizat. Bagi yang membacanya akan mendapatkan pahala dan keistimewaan lainnya. Berbagia model pembacaan, mulai dari sekedar membaca sebagai ibadah ritual, membaca untuk memahami maknanya, hingga model membaca untuk berbagai kepentingan lainnya. Fenomena semacam ini, dalam kajian Islamic Studies masuk dalam kajian living Qur'an. Yakni suatu kajian bagaimana seseorang menerima dan bereaksi terhadap Alquran dengan cara menerima, merespon, memanfaatkan dan menggunakanya, baik sebagai teks yang memuat susunan sintaksis, atau sebagai mushaf yang memiliki maknanya sendiri. ${ }^{10}$

Adapun makna surat-surat yang dibaca ketika tradisi Ngabdul Qodiran dapat dilihat dari pandangan dua lapis masyarakat, yaitu menurut para tokoh dan menurut masyarakat umum:

a. Menurut Para Tokoh

Sebagai orang yang langsung mendapat ijazah Ngabdul Qodiran, Abah Kiai menjelaskan bahwa makna pembacaan suratsurat Alquran dalam tradisi Ngabdul Qodiran adalah ta'abbudd li amrillāh - ibadah yang dilakukan hanya semata mata karena Allah. Menurutnya mencari makna atau maksud pembacaan Alquran tidak perlu dilakukan meski ada yang mengatakan misalnya membaca surat al-Waqi'ah itu akan memperluas rizki atau memudahkan sesuatu. Baginya, itu hanyalah hadiah, bukan tujuannya. Ia menganalogikan dengan orang yang menyebrangi sungai, lalu mendapatkan kesegaran. Tujuanya adalah sampai ke seberang. Tapi kemudian dia mendapatkan kesegaran dari air sungai tersbut. Sama halnya dengan

10 Ahmad Rafiq, "Sejarah Al Qur'an: dari Pewahyuan ke Resepsi (Sebuah Pencarian Awal Metodologis )" In Islam, Tradisi dan Peradaban, ed. Sahiron Syamsuddin (Yogyakarta: Suka Press, 2012), 73. 
membaca Alquran dalam Ngabdul Qodiran, tujuan utamanya adalah melaksanakan perintah Allah. Jika kemudian seseorang mendapatkan keluasan rizki atau yang lainnya, maka itu adalah hadiah dari Allah. ${ }^{11}$

Ngabdul Qodiran merupakan salah satu fenomena living Qur'an yang dipraktikkan di Pondok Pesantren Al Luqmaniyyah Yogyakarta. Konsep tersebut kemudian dirumuskan dalam simbol pembacaan surat-surat Alquran. Praktik Ngabdul Qodiran di sana memang sedikit berbeda dengan praktik pada umumnya yang menggunakan pembacaan manakib di dalamnya. Ngabdul Qodiran di sini dilaksanakan dengan membaca beberapa surat Alquran. Secara umum Alquran dapat menjadi obat, rahmat, dan cahaya bagi pembacanya. Akan tetapi masing-masing bagiannya memiliki keistimewaan tersendiri. Seperti surat al-Wāqi'ah itu dapat menghindarkan dari kemiskinan seperti dalam sebuah hadis yang artinya: Dari Abdullah bin Mas'ud berkata: Sungguh aku memerintahkan kepada anak-anak perempuanku untuk membaca surat al-Wāqi'ah setiap malam, karena sesungguhnya aku telah mendengar Rasulullah Saw. bersabda "Barang siapa membaca surat Al Waqi'ah setiap malam maka kefakiran tidak akan menimpanya”.

\section{b. Menurut Masyarkat Umum}

Secara umum, jamaah memaknai surat-surat yang dibaca dalam pelaksanan tradisi Ngabdul Qodiran sebagai sarana doa. Mereka mengaitkannya dengan tujuan pelaksanaan Ngabdul Qodiran. Sebagaimana yang diungkapkan oleh Kang Abdullah, Ngabdul Qodiran adalah amrih keselametan. Menurutnya Ngabdul Qodiran dilakukan untuk mendoakan kerabat yang sedang pergi haji agar diberi keselamatan dan menjadi haji yang mabrur. Pembacaan suratsurat Alquran di dalamnya merupakan sarana yang mencapai tujuan itu.

\section{2) Simbol Tawașșul kepada Syaikh 'Abd al-Qadir al-Jaylanī}

Konsepsi tentang kemuliaan ulama dipercaya dapat mengantarkan para jamaah untuk mendapatkan keselamatan dan kebaikan. Cara yang dilakukan untuk memuliakan ulama dilakukan dengan patuh, mengikuti para Kiai dan ngalap berkah kepada mereka. Konsep ini dirumuskan dengan Tawașul ${ }^{12}$. Tawașsul ini bentuknya bermacam-macam, ada yang

11 Hasil wawancara dengan Abah Naim pengasuh Pondok Pesantren Al Luqmaniyyah Yogykarta, 20 Mei 2019.

12 Tawașsul didefinisikan sebagai upaya mendekatkan diri kepada Allah dengan menggunakan wasilah. Wasilah merupakan sesuatu yang menyambung dan mendekatkan 
dilakukan dengan dengan melakukan amal-amal saleh, menyebut nama orang-orang yang dekat dengan Allah baik dengan yang masih hidup maupun kepada yang telah meninggal dunia. Tawassul dengan cara inilah yang dilakukan oleh jamaah Ngabdul Qodiran Pondok Pesantren Al Luqmaniyyah. Mereka bertawașul kepada Syaikh 'Abd al-Qadir alJaylani dengan cara membaca surat-surat Alquran. Mereka meyakini bahwa Syaikh 'Abd al-Qadir al-Jaylani adalah Sultan Auliya' Wali Quthub walinya para wali yang kewaliannya sudah mu'tabarah. Sehingga sering disebut setelah nama Nabi Muhammad ketika akan berdoa, dengan harapan, agar melaluinya, Allah akan mendengar dan mengabulkan doa yang dipanjatkan.

\section{3) Simbol Ayam Kampung Jago dan Nasi Kebuli}

Simbol ayam kampung dan nasi kebuli dirumuskan dari konsep memuliakan ulama. Menurut Kiai Bukhari, hidangan ini adalah makanan favorit Syaikh 'Abd al-Qadir al-Jaylanī. Untuk menghormati ulama dan ngalap berkah, makanan ini dijadikan makanan khas yang selalu ada disetiap pelaksanaan Ngabdul Qodiran. Hidangan ini merupkan bagian dari ijazah yang berasal dari Kiai Cholil Bangkalan. Simbol-simbol yang dirumuskan tersebut, disampaikan oleh pemilik otoritas -para Kiaikepada masyarakat. Para Kiai menyampaikan simbol yang menawarkan suatu gaya hidup atau tindakan yang didasarkan pada hadis Nabi dengan cara persuasif. Gaya hidup atau tindakan yang disarankan oleh simbolsimbol tersebut diwujudkan dalam bentuk pelaksanaan tradisi Ngabdul Qodiran.

\section{SIMPULAN}

Menurut hemat penulis yang dipadukan dengan teori Clifford Greettz, dalam berkehidupan bermasyarakat, seseorang akan selalu menemukan fenomena-fenomena sozial dan nilai-nilai dalam sebuah fenomena. Oleh karena itu, jangan menghukumi sebuah fenomena akan tetapi haruslah mencari makna dari fenomena tersebut.

Sebagai salah satu fenomena living Qur'an, resepsi pembacaan suratsurat Alquran dalam tradisi Ngabdul Qodiran yang dilakukan oleh jamaah di Pondok Pesantren Al Luqmaniyyah memiliki makna sendiri. Melalui teori interpretasi budaya Clifford Greettz, dapat disimpulkan bahwa jamaah mengenal konsep keutamaan Alquran. Konsep-konsep tersebut didasarkan pada landasan agama yang mempunyai ultimate meaning sebagai cara untuk mendapatkan keselamatan, pahala, syafaat, dan surga.

seseorang dengan Allah atas dasar keinginan yang kuat dari yang bersangkutan untuk mendekat kepada-Nya. Quraish Shihab, Wawasan Al Qur'an tentang Dzikir dan Doa (Jakarta: Lentera Hati, 2006). 
Konsep-konsep itu kemudian dipercaya sebagai konsep yang benar dan nyata. Selanjutnya konsep ini dirumuskan dalma bentuk simbol suratsurat Alquran, tawașul kepada Syaikh 'Abd al-Qadir al-Jaylanī, hidangan berupa nasi kebuli dan ayam kampung jago. Simbol-simbol tersebut memiliki makna yang kembali pada konsep-konsep tersebut. Simbol-simbol tersebut menyarankan suatu gaya hidup atau tindakan yang disampaikan secara persuasif. Selanjutnya konsep tesebut memotivasi masyararkat untuk melakukan tradisi Ngabdul Qodiran. Pelaksanaan tradisi ini kemudian memunculkan perasaan pada diri seseorang. Perasaan yang dialami ketika melakukan tradisi Ngabdul Qodiran ini kemudian direfleksikan dalam kehidupan sehari-hari, seolah membenarkan konsep yang ada, sehingga perasaan tersebut terlihat unik dan reaslistis.

\section{DAFTAR PUSTAKA}

AM, Imron. Kupas Tuntas Masalah Peringatan Haul ,Surabaya: Al-Fikar, 2005.

Greettz, Clifforz. The Interpretation od Cultures. Basic Book: 1973. - Kebudayaan dan Agama (Terj), ed. Fransisco Budi Hariman. Yogyakarta: Kanisius, 1992.

Hasil wawancara dengan Abah Naim pengasuh Pondok Pesantren Al Luqmaniyyah Yogykarta, 20 Mei 2019.

Hasil wawancara dengan Kang Abdullah selaku abdi ndalem, 22 Mei 2019.

Kafid, Nur. 'From Personal to Social Tranformation: A Phenomenological Study on The Life of 'Kiai Kampung" Jurnal Komunitas: Research \& Learning in Sociology and Anthropology Vol 6, No 2 (2014):

Pals, Daniel L. Seven Theories of Religion n.d.

Rafiq, Ahmad. "Sejarah Alquran: dari Pewahyuan ke Resepsi (Sebuah Pencarian Awal Metodologis)," In Islam, Tradisi dan Peradaban, ed. Sahiron Syamsuddin. Yogyakarta: Suka Press, 2012.

Shihab, Quraish. Wawasan Alquran tentang Dzikir dan Doa. Jakarta: Lentera Hati, 2006.

Syam, Nur. Madzhab-Madzhab Antropologis. Yogyakarta: Lkis, 2011.

W.J.S Poewardarminta, Kamus Besar Bahsa Indonesia. Jakarta: Balai Pustaka, 1990. 